\title{
Capacitação da pessoa com deficiência intelectual ao mercado de trabalho numa APAE do sul de Santa Catarina
}

\author{
Empowerment of person with intellectual deficiency to the labor market \\ in an APAE the south of Santa Catarina
}

http://dx.doi.org/10.5007/2178-4582.2016v50n2p437

Laysa Karoline Cardoso

Cristina Adriana Rodrigues Kern

Universidade do Extremo Sul Catarinense, Criciúma/SC, Brasil

\begin{abstract}
Trata-se de um estudo de caso em uma APAE do sul de Santa Catarina, para conhecer as medidas adotadas pela instituição na capacitação para a inclusão da pessoa com deficiência intelectual no mercado de trabalho. Atualmente o número de pessoas com deficiência intelectual no mercado formal de trabalho é consideravelmente menor do que o das pessoas com outros tipos de deficiência e, nessa direção, pretende-se favorecer a reflexão quanto à importância da capacitação dessas pessoas. O delineamento é de natureza qualitativa e para a coleta de dados foi utilizada a análise documental e entrevistas semidirigidas com os professores e equipe multiprofissional envolvidos no processo de capacitação profissional. Os dados foram avaliados a partir da análise de conteúdo. Concluem-se como entraves à inclusão no mercado de trabalho: a falta de perfil dos alunos para as vagas disponibilizadas, dificuldade de desvinculação da família dos alunos aos benefícios recebidos e superproteção familiar.

Palavras-chave: Deficiência intelectual; Inclusão; Capacitação; Mercado de trabalho; APAE.
\end{abstract}

It is about a case study in an APAE the south of Santa Catarina, to know about the adopted actions from the institution in the empowerment to the inclusion of people with intellectual deficiency in the labor market. Nowadays the number of people with intellectual deficiency in the formal market is significantly smaller than the number of people with another kinds of deficiency and, in this direction, it is intended to enhance the consideration to the importance of this people empowerment. The design is from a qualitative nature and to the data collection was used the documentary analysis and the semi-directed interviews were done with the teachers and the multi-professional team involved in the professional empowerment. The data were analyzed based on the contents analysis. These are conclude as barriers to the inclusion to the labor market: the low profile from the students to the available job vacancy. Untying difficulty from the student's family concerning about the earned benefit and family overprotection.

Keywords: Intellectual deficiency; Inclusion; Empowerment; Labor Market; APAE.

\section{Introdução}

O presente estudo adveio de uma reflexão sobre a capacitação da pessoa com deficiência intelectual (DI) como uma medida de inclusão na sociedade, partindo do pressuposto de que o trabalho é uma das principais formas de inclusão social em que o indivíduo tem a possibilidade de demonstrar suas potencialidades e expandir suas perspectivas de vida. A inclusão pode ser definida como um processo bilateral no qual as pessoas com deficiência e a so- 
ciedade buscam, em parceria, tornar realidade o que é proposto em legislação sobre o direito de oportunidades para todos (SASSAKI, 2003).

Para a compreensão atual sobre a deficiência, os termos adotados para se referir a essa população são de grande relevância social, sendo estes compatíveis com os conceitos vigentes e valores de cada sociedade. No Brasil, a busca da terminologia correta na abordagem de assuntos sobre deficiência ocorreu na tentativa de desencorajar práticas discriminatórias para a construção de uma verdadeira sociedade inclusiva (SASSAKI, 2003). O termo pessoa com deficiência intelectual veio substituir e ampliar a conotação de outras denominações utilizadas na lei, "[...] tais como: excepcionais, incapacitados, impedidos, descapacitados, inválidos, portadores de necessidades especiais e etc." (MARANHÃO, 2005, p. 28).

Conforme a Convenção da Organização das Nações Unidas (ONU) sobre os Direitos das Pessoas com Deficiência, incorporada à legislação brasileira em 2008, não é o limite pessoal que demarca a deficiência, mas os obstáculos existentes nos espaços: "no meio físico, no transporte, na informação, na comunicação e nos serviços" (BRASIL, 2012, p. 11). O documento define que as pessoas com deficiência são "aquelas que têm impedimentos de longo prazo de natureza física, mental, intelectual ou sensorial, os quais, em interação com diversas barreiras, podem obstruir sua participação plena e efetiva na sociedade em igualdades de condições com as demais pessoas" (BRASIL, 2012, p. 26).

A participação de trabalhadores com deficiência no mercado de trabalho ainda é baixa quando comparada à participação das pessoas sem deficiência, embora já exista uma exigência legal de cotas (VIOLANTE; LEITE, 2011). Essas informações demonstram que o fator jurídico não está sendo suficiente para reorganizar a realidade dessa população. Atualmente, de acordo com os dados do censo realizado em 2010 , do total de 86,4 milhões de trabalhadores, apenas 20,4 milhões eram pessoas com deficiência (OLIVEIRA, 2012). A DI, "exerceu o maior impacto negativo no nível de ocupação, tanto para os homens como para as mulheres", de acordo com os dados do censo de 2010 (OLIVEIRA, 2012, p. 20).

Atualmente, estudos realizados evidenciam que os avanços legislativos não garantem efetivamente a inclusão da pessoa com DI no mercado de trabalho. $\mathrm{Na}$ busca pelas reais possibilidades de igualdade no tratamento e oportunidades para todos, torna-se evidente a necessidade de criação de mecanismos para que os DI estejam capacitados para atuar no mercado de trabalho. A inclusão social é um processo ao qual a sociedade deve se adaptar para que ela ocorra, no entanto, as pessoas a serem incluídas também 
precisam estar preparadas para assumir os seus papéis (LORENZO, 2016; SANTOS et al., 2016; SASSAKI, 2003; SCUSSIATTO, 2015; SILVA; FURTADO, 2013).

Dentre os aspectos que interferem para que ocorra a inclusão, os autores citam a necessidade de sensibilização das empresas empregadoras pelo entendimento de seu compromisso ético e social, não apenas pelo cumprimento legal das leis, investindo em melhores condições físicas e sociais para esses trabalhadores. Para tanto, também é apontada como necessidade a implantação de serviços de capacitação mais condizentes com a realidade do mercado de trabalho, tanto no que diz respeito às pessoas com DI quanto em relação às empresas, para que haja preparação mais condizente com os pressupostos inclusivos (PHILERENO et al., 2015; SANTOS et al., 2016; SILVA; FURTADO, 2013).

Outra medida referida nos estudos para favorecer a inclusão da pessoa com DI no mercado de trabalho é a capacitação profissional. Esse processo, para que ocorra de forma efetiva, requer que a pessoa com deficiência tenha acesso a instituições especializadas que, através da educação, reabilitação e capacitação profissional, preparem o aluno para que esteja apto a ser incluído no mercado de trabalho. Estas instituições devem desenvolver ações para identificar as potencialidades, aptidões e interesses do aluno para o exercício de uma atividade profissional (COSTA, et al., 2011; MENDES et al., 2004; SASSAKI, 2003).

Nessa direção, pesquisas apontam para a importância da formação profissional, a qual "deve se concentrar no desenvolvimento de habilidades de autodeterminação, entendida como a capacidade de tomar decisões sobre as questões que afetam a sua vida e agir com base nessas escolhas" (HUGHES, 2013; SHOGREN; KENNEDY; DOWSETT; LITTLE, 2014; WEHMAN, 2013; WEHMEYER et al., 2012 apud GOMES-MACHADO et al., 2016, p. 33, tradução nossa) ${ }^{1}$.

A relevância do investimento nessa vertente tem sido destacada, tal como mostra um estudo recente que avaliou os efeitos da formação profissional em um grupo de pessoas com deficiência intelectual.

Um ano após a inclusão no mercado de trabalho, os participantes ainda estavam empregados, com melhorias significativas em aspectos como a aprendizagem, autonomia, desenvolvimento afetivo e social, bem como em relações familiares e comunitárias. A formação profissional contribuiu para o desenvolvimento global das pessoas, favorecendo a sua inclusão profissional,

1 The vocational training process should focus on the development of self-determination skills, understood as the ability to make decisions regarding the questions that affect one's life and to act on the basis of these choices. 
e, como resultado, o sustento, a autonomia, e uma diminuição na necessidade de assistência e apoio (GOMES-MACHADO et al., 2016, p. 33, tradução nossa) ${ }^{2}$.

Diante desse panorama, o foco do estudo foi conhecer as medidas adotadas por uma APAE de SC para a capacitação dos alunos com DI. A pesquisa foi desenvolvida por meio de estudo de caso na instituição e os procedimentos utilizados para a coleta de dados foram análise documental e entrevistas semidirigidas com os professores e equipe multiprofissional envolvidos nesse processo. A relevância social do estudo encontra-se na busca de indicadores que possam expandir o conhecimento e aprimoramento no processo de capacitação de alunos com DI, tendo em vista que as pesquisas demonstram que a capacitação é um dos aspectos que podem contribuir para a melhoria na inclusão dessa população ao mercado de trabalho (LORENZO, 2016; SANTOS et al., 2016; SASSAKI, 2003; SCUSSIATTO, 2015; SILVA; FURTADO, 2013).

\section{A legislação brasileira}

Desde a aprovação feita pela Constituição Federal Brasileira de 1988 da "Declaração Universal dos Direitos Humanos" a qual em seu artigo 23 afirma que: "Toda pessoa tem direito ao trabalho, à livre escolha do seu trabalho e a condições equitativas e satisfatórias de trabalho e à proteção contra o desemprego" (OLIVEIRA, 2012, p. 18), observou-se um maior empenho das políticas públicas para promover a inclusão da pessoa com deficiência no mercado de trabalho. A Lei $n^{\circ} 7.853$, datada de $24 / 10 / 89$, foi a primeira lei que veio dispor sobre o apoio à pessoa com deficiência e sua integração social, instituindo a Coordenadoria Nacional para Integração das Pessoas Portadoras de Deficiência - CORDE (MARANHÃO, 2005). Em seu artigo $2^{\circ}$, esta lei atribui ao poder público a tarefa de: "Assegurar às pessoas portadoras de deficiência o pleno exercício de seus direitos básicos, inclusive dos direitos à educação, à saúde, ao trabalho, ao lazer, à previdência social, ao amparo à infância e à maternidade [...]" (PASTORE, 2000, p. 45). Em seu artigo 8º a lei criminaliza a discriminação do portador de deficiências. "Constitui crime punível com reclusão de 1 a 4 anos, e multa: III - negar, sem justa causa, a alguém, por motivos derivados de sua deficiência, emprego ou trabalho" (PASTORE, 2000, p. 47).

Em 1991, a Lei $\mathrm{n}^{\circ} 8.213 / 91$, artigo 23, passou a determinar que a empresa com 100 ou mais empregados deva preencher de $2 \%$ a $5 \%$ dos seus cargos com

2 One year after inclusion in the labor market (T3), participants were still employed, with significant improvements in such aspects as learning, autonomy, affective and social development, as well as in family and community relations. The vocational training contributed to the global development of persons, favoring their professional inclusion, and as a result, sustenance, autonomy, and a decrease in the need for assistance and support. 
beneficiários reabilitados ou pessoas com deficiência na seguinte proporção: até 200 funcionários, 2\%; de 201 a 500 funcionários, 3\%; de 501 a 1000 funcionários, 4\% e de 1001 funcionários em diante,5\% (MARANHÃO, 2005).

De acordo com os dados do censo realizado em 2010, atualmente, $23,9 \%$ da população residente no país apresenta algum tipo de deficiência visual, auditiva, motora ou intelectual (OLIVEIRA, 2012). Apesar de possuir um conjunto de princípios legais que asseguram oportunidades de trabalho às pessoas com deficiência, a legislação brasileira somente começou a ser observada mediante punições às empresas que não cumprem a lei, por meio da fiscalização mais efetiva do Ministério Público do Trabalho (TOLDRÁ; MARQUE; BRUNELLO, 2010).

Em 2008, o Brasil ratificou a Convenção sobre os Direitos das Pessoas com Deficiência, empregada pela ONU e o Protocolo Facultativo. O documento alcançou a correspondência de emenda constitucional, estimulando a atuação em parceria entre a sociedade civil e o governo, num movimento em prol da democracia (BRASIL, 2012). Assim, em 2009, por meio do Decreto $\mathrm{n}^{\mathrm{o}} 6.949$, em seu artigo 27, a pessoa com deficiência tem os direitos relativos ao trabalho e emprego assegurados:

[...] oportunidade de se manter com um trabalho de sua livre escolha ou aceitação no mercado laboral, em ambiente de trabalho que seja aberto, inclusivo e acessível. [...] Proibir a discriminação baseada na deficiência com respeito a todas as questões relacionadas com as formas de emprego, inclusive condições de recrutamento, contratação e admissão, permanência no emprego, ascensão profissional e condições seguras e salubres de trabalho; [...] condições justas e favoráveis de trabalho, incluindo iguais oportunidades e igual remuneração por trabalho de igual valor, condições seguras e salubres de trabalho, além de reparação de injustiças e proteção contra o assédio no trabalho; Assegurar que as pessoas com deficiência possam exercer seus direitos trabalhistas e sindicais, em condições de igualdade com as demais pessoas; [...] acesso efetivo a programas de orientação técnica e profissional e a serviços de colocação no trabalho e de treinamento profissional e continuado; [...] oportunidades de emprego e ascensão profissional para pessoas com deficiência no mercado de trabalho, bem como assistência na procura, obtenção e manutenção do emprego e no retorno ao emprego; [...] oportunidades de trabalho autônomo, empreendedorismo, desenvolvimento de cooperativas e estabelecimento de negócio próprio; [...] Empregar pessoas com deficiência no setor público [...] no setor privado, mediante políticas e medidas apropriadas, que poderão incluir programas de ação afirmativa, incentivos e outras medidas; i) Assegurar que adaptações razoáveis sejam feitas para pessoas com deficiência no local de trabalho; $[. .$.$] aquisição de experiência de trabalho por pessoas$ com deficiência no mercado aberto de trabalho; [...] reabilitação 
No que dispõe sobre os Planos de Benefícios da Previdência Social, o Benefício de Prestação Continuada (BPC), instituído pela Lei $\mathrm{n}^{\circ} 8.742$ de 07/12/1993, artigo 20, assegura um salário-mínimo mensal à pessoa com deficiência e ao idoso com 65 anos ou mais que comprovem não possuir meios de prover a própria manutenção, nem de tê-la provida por sua família. Em 2011, o Decreto $\mathrm{n}^{\mathrm{o}} 7.617$, art. $47 \mathrm{~A}, \S 1^{\circ}$, referiu que o pagamento do benefício suspenso "será restabelecido mediante requerimento do interessado que comprove a extinção da relação trabalhista ou da atividade empreendedora, e, quando for o caso, o encerramento do prazo de pagamento do seguro-desemprego [...]" (BRASIL, 2011, p. 1).

No que diz respeito à inclusão das pessoas com deficiência no mercado de trabalho a legislação brasileira é considerada uma das mais avançadas. Contudo, a legislação vigente não garante a profissionalização da população com deficiência para o mercado de trabalho, bem como as instituições especializadas nessa população carecem de atualização dos seus planos de ações para a inclusão de seus usuários no mercado de trabalho (MENDONÇA, 2007 apud TOLDRÁ; MARQUE; BRUNELLO, 2010).

\section{A capacitação profissional da pessoa com deficiência intelectual e a proposta inclusiva}

Segundo Mendes et al. (2004) a capacitação para o trabalho da pessoa com deficiência vem sendo discutida partindo do pressuposto de que o trabalho é uma das principais formas de inclusão social, sendo uma atividade fundamental para "[...] desenvolvimento da autoestima, interação social, sentimento de pertinência e capacidade, bem como, construção de identidade e autonomia" (SAINT-JEAN, 2003 apud TOLDRÁ; MARQUE; BRUNELLO, 2010, p. 159).

De acordo com Ribas (1985, apud SAAD, 2003), vivemos em uma estrutura social e econômica muito competitiva em termos de empregabilidade, onde grande parte da sociedade não acredita no bom desempenho do trabalhador com deficiência por não corresponderem às exigências e ao ritmo exigido pela produtividade. Atualmente o mercado de trabalho encontra-se mais conscientizado sobre questões referentes à deficiência, porém não o bastante para a inclusão dessas pessoas (BRASIL, 1999), o que é confirmado pelos dados do CENSO realizado em 2010, ao mostrar a participação ainda baixa daqueles no mercado de trabalho, em comparação às pessoas sem deficiência (OLIVEIRA, 2012). 
Recente revisão de literatura constatou que há "falta de mecanismos de fiscalização adequados, além da necessidade de o Estado promover qualificação das pessoas com deficiência e incentivos para as empresas que cumprem de forma regrada o que estabelece a lei de cotas" (ANTONIASSI, 2015, p. 67).

Segundo Araujo e Schmidt (2006), muitas empresas não cumprem a lei por consequência da baixa escolarização e capacitação oferecida à pessoa com DI. A capacitação para inclusão no mercado de trabalho é considerada uma área prioritária não apenas pelos especialistas, mas também pela pessoa com DI, pois permite que demonstrem suas habilidades e competências, diminuindo a estigmatização sofrida e combatendo a desigualdade de oportunidades (MENDES et al., 2004).

No Brasil, a capacitação da pessoa com DI é realizada por instituições especializadas, por centros de reabilitação e por associações de pessoas deficientes. Para a inclusão da pessoa com deficiência no mercado de trabalho, é imprescindível o apoio das instituições filantrópicas mediante programas que promovam sua capacitação. As modalidades de profissionalização oferecidas vão desde o treinamento para a colocação em emprego competitivo, até o Programa de Emprego Apoiado, passando por alternativas como o Trabalho Protegido (Oficinas) ou Programas de Pré-Profissionalização (SASSAKI, 1997 apud ARAUJO; SCHMIDT, 2006).

A capacitação profissional deve oferecer a oportunidade de a pessoa com deficiência mediar suas relações com o mundo, facilitando a aquisição de sua autonomia. Entretanto, procedimentos adotados por instituições especializadas com práticas assistencialistas, recreativas e protetoras afastam a pessoa com deficiência da realidade do mercado de trabalho competitivo preparando os indivíduos para atividades que não fazem parte da demanda de oferta das empresas (SANTOS et al., 2016; SILVA; PALHANO, 2005).

A família, muitas vezes, pode ser outro fator de dificuldade no processo, quando resiste à proposta de inserção de deficientes no mercado de trabalho, por não acreditar nas capacidades dos mesmos e também por não estar engajada nessa proposta (PHILERENO et al., 2015).

A FENAPAES promove e articula ações em defesa dos direitos das pessoas com deficiência, para a melhoria da qualidade dos serviços prestados pelas APAEs, na perspectiva da inclusão social de seus usuários (FEDERAÇÃO NACIONAL DAS APAEs, 2014). De acordo com o seu Manual para Profissionais e Dirigentes, as instituições devem desempenhar cinco funções básicas para o processo de capacitação profissional: 
1. Identificar potencialidades e interesses da pessoa com deficiência e oferecer programas de educação profissional que deverão identificar-se com a realidade socioeconômica onde se desenvolvem; 2. Capacitar os seus recursos humanos, que estão à frente dos programas de educação profissional; 3. Coordenar, inovar e promover programas e parcerias que possam garantir a qualidade da atividade nela desenvolvida; 4. Sensibilizar e conscientizar a sociedade, principalmente os empregadores, sobre as potencialidades de trabalho da pessoa com deficiência; 5. Informar e conscientizar a pessoa com deficiência e sua família sobre seus direitos e deveres de cidadania (BATISTA et al., 1997, p. 13).

A tendência atual tem sido direcionar os programas de educação para o trabalho aos ambientes regulares, garantindo assim sua integração (MENDES et al., 2004). Nesse modelo inclusivo, a instituição deve preparar a pessoa com deficiência não apenas para receber conhecimentos e habilidades ao exercício de uma ocupação específica, mas também é importante aprender qualidades pessoais relacionadas ao desempenho (BRASIL, 1999).

\section{Associação de Pais e Amigos dos Excepcionais}

Em 1954, na cidade do Rio de Janeiro, devido à ineficiência do Estado, familiares de pessoas com DI ou múltipla deram início a uma mobilização social resultando na criação da primeira APAE do Brasil, a fim de prestar serviços de educação, saúde e assistência social (COSTA, et al., 2011). A rede APAE caracteriza-se por uma organização social na qual o principal objetivo é promover a atenção integral à pessoa com DI ou múltipla, estando presente, atualmente, em mais de 2 mil municípios em todo o território nacional que hoje conta com cerca de 250 mil alunos (FEDERAÇÃO NACIONAL DAS APAEs, 2014).

Entretanto, a FENAPAES reconhece a necessidade de mudança na prestação de programas de educação profissional, pois muitas pessoas com DI têm permanecido grande parte de suas vidas em instituições especializadas sem perspectivas de realização profissional no mercado formal de trabalho (BATISTA et al., 1997).

\section{Caracterização da instituição}

A APAE de SC, onde foi realizado o presente estudo, constitui-se como entidade filantrópica, sem fins lucrativos atendendo gratuitamente seus alunos nas áreas: pedagógica, médica, assistência social, transporte, alimenta- 
ção, atendimento de fisioterapia, psicologia, terapia ocupacional, psiquiatria e odontologia, tendo como principal objetivo a inclusão da pessoa com deficiência na sociedade, na família e no ensino regular. A escola atualmente possui 195 alunos matriculados, na faixa etária de 0 ano até a idade adulta, totalizando 220 atendimentos ao dia, sendo que 25 alunos frequentam a escola em regime de semi-internato (APAE SC, 2014).

A instituição tem como objetivos: capacitação para atuar no mercado de trabalho ou para desenvolver trabalho supervisionado; auxiliar no encaminhamento de alunos qualificados para o mercado de trabalho; atender aspectos educacionais e clínicos, visando superar atrasos sensório-perceptivos, psicomotores, de linguagem e de socialização; sensibilizar os órgãos governamentais sobre as legislações visando eliminar barreiras; realizar parceria com as escolas do ensino regular, repassando orientações aos professores, quando estes prestam atendimento à pessoa com deficiência; receber estagiários de diversas áreas de formação, fazendo as devidas orientações e avaliações; fazer atendimento pedagógico a alunos e professores; garantir a função social da escola de socialização do conhecimento; orientar os profissionais sobre avaliação psicopedagógica dos alunos; orientar pais e professores sempre que necessário; conscientização sobre a prevenção de deficiências e inclusão da pessoa com deficiência na sociedade; participar de reuniões de pais, irmãos, equipe multidisciplinar, estudo e pedagógica; promover a articulação entre escola, família e comunidade; promover mudança e adaptação dos alunos em sala de aula sempre que necessário; promover o aperfeiçoamento permanente dos professores, através de reuniões pedagógicas e encontros de estudos; realizar encaminhamentos e informações aos professores, equipe multidisciplinar e pais de alunos, sempre que necessário; realizar visitas a escolas regulares e às famílias sempre que necessário; propiciar carteira, transporte gratuito e encaminhamento de pensões especiais com relatórios de reavaliação mensal (APAE SC, 2014).

\section{Oficina Protegida Terapêutica}

De acordo com Projeto Político Pedagógico da instituição, o setor de OPT, tem como objetivo apropriar-se de conceitos científicos e das relações de educação, trabalho e acessibilidade, buscando a resolução de situações problemas, sendo a escola a principal mediadora do processo para que o educando se torne um sujeito autônomo e autor do aprendizado. São desenvolvidas ações pedagógicas de língua portuguesa, matemática, ciências, história, geografia e ensino religioso (APAE SC, 2014). 
O setor de educação e trabalho tem o objetivo de preparar o educando para inclusão no mercado de trabalho formal e informal. Para isso são desenvolvidos projetos envolvendo a confecção de estopas e tapeçarias. O projeto estopa foi desenvolvido para auxiliar nas habilidades manuais dos educandos, a satisfação de sentir-se útil, além da necessidade de ampliar as atividades laborativas do setor visando maior autonomia e independência. O projeto tapeçaria tem como objetivo desenvolver a consciência ambiental no processo de reaproveitamento de material, habilidades manuais, criatividade e apropriação de novos conhecimentos (APAE SC, 2014).

\section{Método}

O presente estudo é de natureza qualitativa, descritiva e exploratória. A metodologia qualitativa possibilita que se descubra a razão de ser daquilo que nos propomos a investigar (HAGUETTE, 2003). Por meio da pesquisa qualitativa, busca-se "melhor compreender o comportamento e experiência humanos, entender o processo pelo qual as pessoas constroem significados e descrever o que são aqueles significados" (BOGDAN; BIKLEN, 1998, p. 38). Ainda esses autores, referem o ambiente natural como a fundamental fonte de dados; o próprio pesquisador como o principal instrumento e o interesse investigativo voltado mais ao processo do que ao resultado.

\section{Participantes}

Os sujeitos da pesquisa são 5 profissionais envolvidos na capacitação dos alunos com DI participantes da OPT em uma APAE de SC: 2 professoras, 1 psicóloga, 1 assistente social e 1 pedagoga.

\section{Procedimentos}

A escolha da instituição a ser estudada foi feita a partir da experiência de Estágio na Área Social, em que foi possível observar e participar do processo de capacitação profissional realizado pela instituição, reconhecendo a importância do tema a ser pesquisado. Obtida a aprovação do Comitê de Ética em Pesquisa da Universidade do Extremo Sul Catarinense - UNESC e o aceite de uma APAE situada ao sul de SC, foi possível a realização do estudo.

A pesquisa foi desenvolvida por meio de um estudo de caso e foram utilizados como instrumentos na coleta de dados: a análise documental e as entrevistas semiestruturadas com os professores da capacitação e demais profissionais envolvidos na preparação profissional dos alunos. A proposta inicial incluía a utilização da técnica de observação participante, entretanto 
não foram preenchidos todos os critérios de inclusão para sua realização, pois nem todos os pais assinaram o TCLE.

A primeira etapa deste trabalho foi a realização das entrevistas semiestruturadas, as quais foram gravadas com o consentimento dos profissionais envolvidos na capacitação dos alunos com DI, participantes da OPT. As entrevistas foram realizadas com 2 professoras, 1 psicóloga, 1 assistente social e 1 pedagoga. A entrevista como técnica de coleta de dados “[...] permite a captação imediata e corrente da informação desejada, praticamente com qualquer tipo de informante e sobre os mais variados tópicos" (LUDKE; ANDRÉ, 1986, p. 34). Na entrevista semiestruturada as questões seguem uma ordem predeterminada, podendo ser respondidas com grande liberdade pelo entrevistado. Além disso, o pesquisador pode acrescentar uma questão não prevista, dependendo das respostas dos entrevistados (MOREIRA, 2002).

$\mathrm{Na}$ segunda etapa foi realizada a pesquisa documental para melhor compreensão do processo de inclusão na especificidade da capacitação profissional das pessoas com DI ao mercado de trabalho. Esse tipo de procedimento de coleta de dados tem sido amplamente utilizado na pesquisa qualitativa, inclusive na área de educação, buscando identificar informações existentes em documentos a partir de questões ou hipóteses relevantes (LUDKE; ANDRÉ, 1986). "Os documentos constituem também uma fonte poderosa de onde podem ser retiradas evidências que fundamentem afirmações e declarações do pesquisador" (LUDKE; ANDRÉ, 1986, p. 39). Durante a análise documental, foi utilizado o Projeto Político Pedagógico da instituição para maiores informações quanto às ações realizadas pela OPT, alguns requerimentos de empresas da região, visando o cumprimento do Art. 93 da Lei ${ }^{\circ}$ 8.213/91 e Notificação do Ministério Público do Trabalho quanto à relação de pessoas com DI interessadas em ingressar no mercado de trabalho para instituir o direito garantido por lei.

\section{Análise dos dados}

A organização e análise dos dados foram realizadas a partir da metodologia de Análise de Conteúdo proposta por Bardin (1977). Na primeira fase, denominada pré-análise, foi realizada a leitura flutuante dos documentos, dos registros e da transcrição das entrevistas (BARDIN, 1977). Em seguida, foram realizadas reflexões sobre o conteúdo de todo o material e definidos os "elementos obtidos por meio da decomposição do conjunto da mensagem" e as unidades de contexto do qual faz parte a mensagem (GOMES, 2001, p. 75). Nessa direção, foram selecionados trechos significativos e definidas catego- 
rias, de acordo com os objetivos e questões do estudo (BARDIN, 1977; GOMES, 2001). As unidades de registro, obtidas através da análise documental e entrevistas, foram agrupadas de acordo com o que têm em comum em termos de enunciação, sempre tendo como norte os objetivos do estudo para a formação das categorias dos dados obtidos. As unidades de registro utilizadas para análise e discussão dos resultados foram as seguintes: medidas de capacitação utilizadas para a inclusão da pessoa com DI no mercado de trabalho; mediação entre a instituição e as empresas; dificuldades para a inclusão no mercado de trabalho.

\section{Resultado e discussão}

Medidas de capacitação utilizadas para a inclusão da pessoa com DI no mercado de trabalho

De acordo com o Projeto Político Pedagógico desenvolvido pela APAE pesquisada, a capacitação das pessoas com DI é realizada pelo setor de OPT, o qual atende um total de 25 alunos. Nesse setor são desenvolvidas ações pedagógicas (ensino da língua portuguesa, matemática, ciências, história, geografia, ensino religioso) e projetos envolvendo a confecção de estopas e tapeçarias. Essas ações visam à aquisição da autonomia, habilidades e competências do aluno, tendo como objetivo o seu encaminhamento para o mercado de trabalho (APAE SC, 2014).

Os alunos participantes da OPT permanecem na instituição em período integral, sendo um período destinado às ações pedagógicas e outro para os projetos desenvolvidos para a confecção de produtos artesanais. O material utilizado para a confecção de tapeçarias, estopas e demais produtos é disponibilizado por empresas de confecção da região e pela própria instituição. Todo o dinheiro arrecadado na venda dos produtos é investido na própria oficina e fica sob a responsabilidade da instituição. Os profissionais entrevistados enfatizaram que as práticas utilizadas nos projetos artesanais possibilitam a aquisição da autonomia do aluno.

Outra ação utilizada para inclusão dos alunos com DI são as parcerias com empresas da região. São realizadas visitas anuais nas quais os alunos têm a possibilidade de conhecer a empresa, as vagas disponibilizadas, além de ter a oportunidade de constatar a presença de pessoas com deficiência que já estão inclusas nessas organizações, possibilitando uma perspectiva positiva quanto a sua inclusão no mercado de trabalho formal. No ano da pesquisa foram realizadas visitas a três empresas da região. 
Atualmente, dos 25 alunos participantes da OPT, 12 possuem benefício de prestação continuada (BPC). Constatou-se que a instituição desenvolve ações através de visitas as empresas, encontros grupais e palestras para incentivar os alunos que recebem benefício, bem como estimular aqueles que ainda estão em processo de capacitação, a optarem pela inclusão no mercado formal de trabalho. No entanto, observa-se falta de apoio da família nesse aspecto, que opta por permanecer com a segurança do benefício. Igualmente, estudos evidenciam que a família se torna um obstáculo à empregabilidade na medida em que não adota ações que promovam autonomia à pessoa com DI (SASSAKI, 2003; SILVA; FURTADO, 2013).

Constata-se que as ações desenvolvidas ainda não são suficientes para sua inclusão no mercado de trabalho formal, pois o número de alunos que efetivamente são incluídos nas empresas tem sido baixo.

\section{Mediação entre a instituição e as empresas}

A instituição estudada é atualmente a única no seu município a desenvolver programas que visam contribuir para a capacitação profissional e inclusão da pessoa com DI no mercado de trabalho. Constatou-se, por meio de documentos recebidos pela instituição sobre vagas para admissão de pessoas com deficiência, que o número de empresas que buscam a instituição para a contratação dos alunos tem sido efetivo. Contudo, observa-se que as contratações ocorrem, em sua maioria, em cumprimento à legislação de política de cotas do Art. 93 da Lei no 8.213/91 e não pela real importância da proposta social em sua essência.

Ao receber de empresas os documentos referentes às vagas disponibilizadas, a instituição faz o levantamento dos alunos que correspondam às exigências da vaga, e viabiliza o encaminhamento do mesmo. Em um primeiro momento o aluno realiza visita à empresa acompanhado da psicóloga da instituição, a fim de verificar se o aluno está apto a ser incluído nas condições da vaga proposta, respeitando o interesse do aluno. Contudo, a psicóloga entrevistada afirmou que a requisição foi respondida negativamente, visto que nenhum dos alunos se encontrava apto para a contratação. Quanto a isso, esclareceu-se que os alunos ainda estão em processo de capacitação.

A Organização Internacional do Trabalho, ao se referir à questão do emprego para a pessoa com deficiência, afirma que ao buscar uma atividade economicamente rentável, esta não deve corresponder apenas às deficiências do candidato, mas às suas aptidões e à sua potencialidade (BATISTA et al., 1997). Neste aspecto, as medidas utilizadas na APAE vão ao encontro do que aponta a literatura, pois para encaminhar os alunos às vagas, realiza-se um levanta- 
mento levando em consideração a potencialidade e interesse de cada aluno, conforme referido por um dos professores entrevistados: "[...] durante todas as atividades realizadas é feita observação constante das aptidões e também interesses de cada um" (informação verbal).

A legislação brasileira começou a ser reconhecida pelas empresas mediante a fiscalização do Ministério Público do Trabalho (Decreto $\mathrm{n}^{\circ}$ 3299/99). A efetivação dessa fiscalização foi constatada na instituição pesquisada através do documento da notificação requisitória quanto ao número de pessoas com deficiência aptas para a inclusão no mercado de trabalho.

Outro aspecto é que o fato da pessoa com DI ser contratada, não garante que haja legitimamente a igualdade de oportunidades. De acordo com as entrevistas, não há um trabalho na empresa para uma recepção diferenciada a esse trabalhador, ficando apenas a cargo da instituição selecionar o aluno que melhor responderá às exigências da vaga. Ao longo da realização da pesquisa, dois alunos foram incluídos no mercado de trabalho, mas apenas um permanece na vaga, pois como foi explicado por um dos entrevistados, o outro aluno não conseguiu responder às exigências do local de trabalho, devido à dificuldade por parte da empresa em acolher de forma mais eficaz essa população. Nessa direção, a literatura aponta que é crucial a responsabilidade do meio social em fornecer suportes físicos, psicológicos, sociais e instrumentais que possibilitem a participação das pessoas deficientes na vida comunitária (ARANHA, 2002) e, nessa perspectiva:

Uma empresa inclusiva é, então, aquela que acredita no valor da diversidade humana, contempla as diferenças individuais, efetua mudanças fundamentais nas práticas administrativas, implementa adaptações no ambiente físico, adapta procedimentos e instrumentos de trabalho [...] (SASSAKI, 2003, p. 65).

Conforme a literatura, essa realidade pode ser compreendida por dois caminhos. Por um lado, há escassez de programas de profissionalização com foco no desenvolvimento de habilidades sociais e emocionais e, no que se refere às empresas, há falta de incentivo financeiro para disporem de melhores condições sociais no ambiente de trabalho, abrangendo principalmente o seu quadro de funcionários para receber as pessoas com deficiência em inclusão (TANAKA; MANZINI, 2005 apud SILVA; FURTADO, 2013). Outra pesquisa na mesma orientação evidenciou, a partir do prisma das empresas, que os programas de qualificação desenvolvidos pelas instituições são ineficientes, ao ponto da não contratação desse público. Esse cenário aponta para a necessidade de atualizar as práticas e planos de ação desenvolvidos por essas 
entidades para a requalificação após a inclusão das pessoas com deficiência (PHILERENO et al., 2015).

Pesquisas realizadas com pessoas com deficiência apontaram que os participantes reconheceram se deparar com dificuldades em âmbito estrutural e de recursos humanos, demonstradas, inclusive, em situações de preconceito e discriminação no ambiente de trabalho, o que revela mais uma vez a necessidade de estratégias que envolvam a mediação entre a instituição profissionalizante e empresa contratante, uma mudança na postura empresarial e também nas políticas públicas (LORENZO, 2016; SANTOS et al., 2016; SILVA; FURTADO, 2013).

Portanto, os dados obtidos apontam que algumas empresas não estão preparadas para receber as pessoas com DI, pois os profissionais entrevistados, bem como a literatura, advertem que para alcançar resultados positivos são necessárias medidas de apoio que acolham essas pessoas no local de trabalho.

\section{Dificuldades para a inclusão no mercado de trabalho}

A partir dos dados obtidos nas entrevistas, a família foi apontada como um fator a ser trabalhado para que não seja um entrave ao processo de capacitação e futura ocupação desses alunos. Em um contraponto aos próprios objetivos da OPT de desenvolver a independência e autonomia do aluno, está a preferência de algumas famílias pela permanência na instituição para a manutenção do Benefício de Prestação Continuada. Um dos motivos levantados para essa ocorrência foi o receio por parte dos responsáveis, de que algo dê errado no trabalho e então percam o benefício, o que não seria um motivo real, pois a regulamentação já prevê que isso possa acontecer e assegura o benefício por dois anos após a contratação pela empresa. Além disso, o Decreto $n^{0} 7.617$, art. 47A, $\S 1^{\circ}$, de 2011 esclarece que o pagamento do benefício pode ser requerido ao ser comprovado o término do contrato trabalhista (BRASIL, 2011).

Outra questão apontada nas entrevistas é que algumas famílias são muito protetoras, veem seus filhos de forma mais dependente do que são na realidade. Quanto a esse aspecto, conforme recomendação da Federação Nacional das APAEs, as famílias devem ser orientadas e trabalhadas de forma que possam reconhecer seus filhos como pessoas capazes e que possam incentivá-los a serem produtivos, desde a entrada na instituição (BATISTA et al., 1997).

Os próprios alunos foram referidos nas entrevistas como objeto necessário de intervenção e, em alguns casos, mesmo que tenham condições para a inclusão no mercado de trabalho, acabam abdicando desse direito para permanecer com a segurança do benefício. Esse resultado foi ao encontro de outro estudo 
de caso realizado em APAEs: "os alunos com deficiência intelectual explicitam seus receios diante da possibilidade de perder o benefício do governo ou de não terem a autonomia requisitada num possível trabalho" (COSTA, et al., 2011, p. 212).

A criação de parcerias com as empresas foi considerada pelos profissionais entrevistados, outra estratégia para ampliar as oportunidades de inclusão da pessoa com DI. Os profissionais sugerem a ocorrência de treinamento para as vagas disponíveis na própria empresa contratante, visando uma aproximação do aluno com a realidade da organização, visto que as exigências impostas pelas empresas, muitas vezes, estão além de suas habilidades, conforme evidencia o depoimento do psicólogo entrevistado na pesquisa: "[...] a empresa nos solicitou um aluno que não estava preparado, colocamos no mercado de trabalho e não ocorreu de maneira efetiva" (informação verbal).

Dentro das medidas necessárias para o melhor andamento da OPT, foi referida a necessidade de reciclagem para que a turma contenha apenas alunos que correspondam ao perfil da oficina: deficiência intelectual moderada com idade a partir de 16 anos.

Outro dado apontado como barreira para a inclusão da pessoa com DI foi a falta de perfil para as vagas disponibilizadas. Partindo desse ponto, observa-se que o trabalho realizado pela OPT auxilia no desenvolvimento da autonomia do aluno, no entanto não é disponibilizada capacitação profissional condizente com a realidade do mercado de trabalho (PHILERENO et al., 2015).

Os dados das entrevistas foram ao encontro dos estudos realizados sobre a capacitação profissional da pessoa com DI no Brasil verificaram que as práticas executadas nas oficinas pedagógicas e/ou protegidas apresentam contradições. Essas contradições são entendidas como resultantes do desafio de compatibilizar as atividades do ensino com as da produção e de adequar suas necessidades pessoais às exigências do mercado de trabalho, sendo desfavoráveis para os mesmos (GOYOS, 1986; MANZINI, 1989; SILVA, 2000 apud SILVA, PALHANO, 2005). Além disso, para que a inclusão ocorra de maneira efetiva é necessário que a instituição esteja atualizada com a demanda do mercado de trabalho, funcionando como articuladora junto a órgãos públicos e empresas privadas, garantindo as parcerias necessárias (BATISTA et al., 1997). Outro trabalho de revisão apresentou o posicionamento de vários autores sobre pontos críticos na educação para o trabalho dos portadores de deficiência, dentre os quais, "a precariedade dos programas vocacionais realizados nas instituições especializadas (GONÇALES, 1999 apud MENDES et al., 2004, p. 114), a desvinculação destes à realidade do trabalho competitivo" (COSTA, 1988; MARTINEZ, 1985; MELETTI, 1997; NEVES, 1999; PA- 
CHECO, 1997; RIBEIRO, 1985 apud MENDES et al., 2004, p. 114), levando a um isolamento das oficinas em relação à realidade social da comunidade $\mathrm{e}$ dificultando a logística do encaminhamento de seus aprendizes para o mercado de trabalho.

Em síntese, dentre as dificuldades para a inclusão apresentadas nas entrevistas estão: a família, o participante das oficinas, as empresas e a própria instituição em sua forma de realizar o processo de capacitação. Assim sendo, observa-se, em concordância com outros estudos sobre o tema, a necessidade de: orientar as famílias de pessoas com deficiência para transformá-las em ponto de apoio e incentivo, assim como orientar as empresas para modificar as representações sociais sobre os portadores de deficiências; rever a proposta da instituição quanto à capacitação para o trabalho do indivíduo portador de deficiências; planejar procedimentos de treinamento e acompanhamento profissionalizantes; realizar programas de capacitação aos instrutores dos portadores de deficiências em oficinas pedagógicas e oficinas protegidas e ampliando a formação profissional de forma que considere os direitos e deveres deste indivíduo enquanto trabalhador (MENDES et al., 2004).

\section{Conclusão}

A proposta de capacitação profissional na APAE estudada visa colaborar para a assunção do aluno em um espaço no mercado de trabalho. As oficinas são potencialmente vantajosas como dispositivo de ensino de uma atividade que pode ser profissional e como um recurso para trabalhar outros âmbitos da vida do aluno. Contudo, os dados decorrentes desse estudo de caso identificaram que a capacitação profissional apresenta muitos desafios, apesar de termos em nosso país a base constitucional e princípios legais que asseguram às pessoas com deficiência a participação na sociedade em igualdade de condições com as demais pessoas.

Em documentos oficiais para profissionais e dirigentes da FENAPAES, existe uma série de orientações para que a profissionalização trabalhe a autonomia dos alunos com DI e efetive a inclusão no mundo do trabalho. No entanto, ao considerar o presente estudo e os dados apontados na revisão bibliográfica, constatou-se que a prática nas empresas está distante de abarcar o que é assegurado nas leis, visto que as pessoas com DI se encontram em desvantagem durante a contratação. Na mesma direção, aquilo que é observado nas regulamentações da FENAPAES não é aplicado na íntegra. Estudos anteriores realizados em cinco APAEs (COSTA et al., 2011, p. 212) apresentam como fatores de risco ao sucesso da capacitação no seu objetivo final, de inserção ao mercado: "o mercado de trabalho local, a formação dos professores, enfo- 
ques dos dirigentes e lideranças de cada APAE, que influencia diretamente a maneira como o ensino profissionalizante é operacionalizado e conduzido."

Os dados desse e de outros estudos de caso em APAES (COSTA et al., 2011), apontaram para a necessidade de um trabalho mais efetivo junto às famílias, oferecendo esclarecimentos quanto às políticas públicas e as perspectivas de trabalho para que a pessoa com DI tenha a possibilidade real de inclusão. As famílias, em função das garantias do BPC, resistem à profissionalização de seus filhos com receio de perdê-los, explicitando a precariedade econômica que grande parte dessa população ainda vive no país. Quanto a isso, considerando que a APAE é uma instituição que recebe estagiários de todas as especialidades, dentre elas a Psicologia, sugere-se a abertura de estágio na área de Psicologia Organizacional, a fim de auxiliar no atendimento da demanda detectada. Nessa perspectiva, a instituição poderia contar com mais recursos humanos para auxiliar na mediação entre a instituição e as empresas, além de auxiliar no trabalho com as famílias, propiciando as informações necessárias quanto à legislação vigente e proporcionando um trabalho de reflexão sobre seus próprios sentimentos acerca do tema da autonomia e dependência dos filhos.

Outra questão que coincidiu com estudos semelhantes a esse, refere-se à falta de mobilização da equipe no sentido de reunir-se para discutir sobre a concretização da inserção desses alunos participantes das capacitações (COSTA et al., 2011).

Ao longo da revisão e da pesquisa, mapearam-se os vários elementos contributivos para que a participação das pessoas com DI na sociedade ocorra em igualdade. Pôde-se averiguar que algumas empresas não estão preparadas para receber as pessoas com DI e o fazem apenas para o cumprimento da lei. Países como EUA e Espanha, têm adotado o modelo de profissionalização da pessoa com deficiência intelectual denominado 'o emprego apoiado'. Considerado o método mais eficiente, o emprego apoiado tem como objetivos garantir um emprego no mercado comum, treinar de acordo com o cargo a ser ocupado, integrar no ambiente do trabalho as pessoas com deficiências de qualquer nível ou grau e, mediante ao acompanhamento de suas atividades, garantir sua permanência no cargo conquistado (BRASIL, 1999). O emprego apoiado realiza o treinamento no local regular de trabalho e é concebido com a supervisão de um "profissional especializado, um instrutor, que auxilia o indivíduo a encontrar um emprego e o capacita nas tarefas pertinentes à sua função no próprio ambiente em que se desenvolve o trabalho, acompanhando -o sistematicamente em suas atividades" (MUNTANER, 1995; SILVAN, 1992 apud MENDES et al., 2004, p.106). 
Por fim, constatou-se como limitação do estudo não ter entrevistado os pais e alunos, o que possibilitaria escutar deles próprios os motivos referidos nas entrevistas com a equipe como entraves à inclusão.

Nessa perspectiva, um dos aspectos que poderia ser investigado é acerca do sentido da insistência na manutenção do BPC, além dos aspectos relativos ao que os entrevistados denominaram superproteção. Com isso sugere-se que pesquisas posteriores abranjam em seu estudo a entrevista com os familiares e com alunos.

\section{Referências}

ANTONIASSI, Gabriela Mayumi Kavano. As pessoas com deficiência e o direito ao trabalho. 2015. 69 f. Trabalho de Conclusão de Curso (Graduação em Direito) - Centro Universitário Antonio Eufrásio de Toledo - Toledo: Presidente Prudente- SP, 2015. Disponível em: $<$ http://intertemas.toledoprudente.edu.br/revista/index.php/Juridica/article/view/5204/4957> Acesso em: 11 abr. 2016

APAE SC. Projeto político pedagógico. SC: APAE de SC, 2014.

ARANHA, M. S. F. A sociedade brasileira, a pessoa que apresenta necessidades especiais, a acessibilidade e a construção de uma sociedade inclusiva. Boletins, 2002. Disponível em: <http: www.tvebrasil.com.br/salto/boletins2002/feei/tetxt1.htm>. Acesso em: 13 mar. 2015.

ARAUJO, Janine Plaça; SCHMIDT, Andréia. A inclusão de pessoas com necessidades especiais no trabalho: a visão de empresas e de instituições educacionais especiais na cidade de Curitiba. Revista Brasileira de Educação Especial, Marília, v. 12, n. 2, p. 241-254, ago. 2006. Disponível em: <http://www.scielo.br/scielo.php?script=sci_arttext\&pid=S1413-65382006000200007> Acesso em: 14 maio. 2014

BARDIN, L. Análise de conteúdo. Lisboa: Edições 70, 1977.

BATISTA, C. et al. Educação profissional e colocação no trabalho: uma nova proposta de trabalho junto à pessoa portadora de deficiência. Brasília: Federação Nacional das APAEs, 1997. $101 \mathrm{p}$.

BOGDAN, R. C; BIKLEN, S. K. Qualitative research for education: introduction for theory and methods. 3. ed.. Boston: AllynAnd Bacon. 1998.

BRASIL. Lei no ${ }^{\mathbf{~}} \mathbf{8 . 7 4 2}$ de 20 de dezembro de 1993. Dispõe sobre a organização da Assistência Social. Disponível em: <http://www.planalto.gov.br/ccivil_03/LEIS/L8742.htm\#art20> Acesso em: 22 ago. 2014.

Ministério da Educação. Educação especial: tendências atuais / Secretaria de Educação a Distância. Brasília: SEED, 1999. 96 p. Disponível em: < http://www.dominiopublico.gov. br/download/texto/me002692.pdf $>$ Acesso em: 11abr.2016. 
. Decreto no 6.949, de 25 de agosto de 2009. Promulga a Convenção Internacional sobre os Direitos das Pessoas com Deficiência e seu Protocolo Facultativo, assinados em Nova York, em 30 de março de 2007. Disponível em: <http://www.planalto.gov.br/ccivil_03/ ato2007-2010/2009/decreto/d6949.htm > Acesso em: 11 abr. 2016.

Decreto $\mathbf{n}^{0}$ 7.617, de 17 de novembro de 2011. Altera o Regulamento do Benefício de Prestação Continuada, aprovado pelo Decreto n. 6.214, de 26 de setembro de 2007. Disponível em: <http://www.planalto.gov.br/ccivil 03/ Ato2011-2014/2011/Decreto/D7617.htm > Acesso em: 22 ago. 2014.

Convenção sobre os Direitos das Pessoas com Deficiência: Protocolo Facultativo à Convenção sobre os Direitos das Pessoas com Deficiência: Decreto Legislativo $n^{\circ} 186$, de 09 de julho de 2008: Decreto $n^{\circ} 6.949$, de 25 de agosto de 2009. 4. ed., rev. e atual. Brasília: Secretaria de Direitos Humanos, 2012. 100 p. Disponível em: < http://www.pessoacomdeficiencia.gov.br/ app/sites/default/files/publicacoes/convencaopessoascomdeficiencia.pdf $>$ Acesso em: 11 abr. 2016.

COSTA, M. C. A. et al. Inclusão social pelo trabalho: a qualificação profissional para pessoas com deficiência intelectual. Revista Interinstitucional de Psicologia, p. 200-214, jul./ dez., 2011. Disponível em: <http://www.fafich.ufmg.br/gerais/index.php/gerais/article/viewFile/190/214>. Acesso em: 15 maio 2014.

FEDERAÇÃO NACIONAL DAS APAEs. Movimento Apaeano: a maior rede de atenção à pessoa com deficiência. Disponível em: $<$ http://www.apaebrasil.org.br/artigo.phtml?a=2> . Acesso em: 9 maio 2014.

GOMES, R. A. Análise de dados em pesquisa qualitativa. In: MINAYO, Maria Cecília de Souza (Org.). Pesquisa social: teoria, método e criatividade. 19.ed. Petrópolis, RJ: Vozes, 2001.

GOMES-MACHADO, Maria Luiza et al. Effects of Vocational Training on a Group of People with Intellectual Disabilities. Journal of Policy and Practice in Intellectual Disabilities, v. 13, p. 33-40, mar. 2016. Disponível em <http://onlinelibrary.wiley.com/doi/10.1111/jppi.12144/ epdf?r3 referer $=$ wol\&tracking action $=$ preview click\&sho $>$.w checkout $=1 \&$ purchase refer-

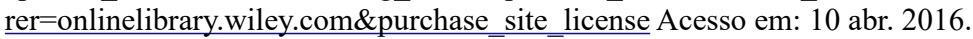

HAGUETTE, T. M. F. Tratado da metodologia da pesquisa clínico-qualitativa: construção teórico-epistemológica, discussão comparada e aplicação nas áreas da saúde e humanas. Rio de Janeiro: Vozes. 2003.

LORENZO, Suelen Moraes. Inserção de pessoas com deficiências no mercado formal de trabalho a partir da percepção dos profissionais de recursos humanos das empresas. 2016. 138 f. Dissertação (Mestrado em Educação) - Universidade Estadual Paulista. Faculdade de Filosofia e Ciências. Marilía, 2016. Disponível em: <http://repositorio.unesp.br/bitstream/handle/11449/136269/lorenzo_sm_me_mar.pdf? sequence=4\&isAllowed=y $>$. Acesso em: 17 abr. 2016.

LUDKE, M.; ANDRÉ, M. E. D. Pesquisa em educação: abordagens qualitativas. São Paulo: Pedagógica e Universitária, 1986. 99 p.

MARANHÃO, R. O. O portador de deficiência e o direito do trabalho. São Paulo: $\mathrm{LTr}$, 2005. 150 p. 
MENDES, Enicéia Gonçalves et al. Estado da arte das pesquisas sobre profissionalização do portador de deficiência. Temas psicologia, Ribeirão Preto, v. 12, n. 2, p. 105-118, 2004. Disponível em: <http://pepsic.bvsalud.org/scielo.php?pid=S1413=389-2004000200003X\&scriptsci_arttext>. Acesso em: 7 abr. 2014.

MOREIRA, D. A.O método fenomenológico na pesquisa. São Paulo: Pioneira Thomson, 2002. $152 \mathrm{p}$.

OLIVEIRA, Luiza Maria Borges. Cartilha do Censo 2010: pessoas com deficiência. Brasília: SDH-PR/SNPD, 2012. $32 \mathrm{p}$.

PASTORE, J. Oportunidades de trabalho para portadores de deficiência. São Paulo: LTr, 2000. $245 \mathrm{p}$.

PHILERENO, Deivis Cassiano et al. Qualificação das pessoas com deficiência para o mercado de trabalho: um estudo de caso em Caxias do Sul - RS. Estudo \& Debate, Lajeado, v. 22, n. 1, p. 160-179, 2015. Disponível em: <http://www.univates.br/revistas/index.php/estudoedebate/ article/viewFile/1312/740>. Acesso em: 10 abr. 2016.

SAAD, S. N. Preparando o caminho da inclusão: dissolvendo mitos e preconceitos em relação à pessoa com Síndrome de Down. São Paulo: Vetor, 2003. 304 p.

SANTOS, José Vitor Palhares et al. Políticas de Inclusão de pessoas com deficiência no mercado de trabalho: uma análise sobre o caso de Lavras (MG). Revista Foco, v. 8, n. 2, p.4-15, ago./ dez., 2016. Disponível em: <http:/www.novomilenio.br/periodicos/index.php/foco/article/ view/173/114>. Acesso em: 17 abr. 2016.

SASSAKI, R. K. Inclusão: construindo uma sociedade para todos. Rio de Janeiro: WVA, 2003. $174 \mathrm{p}$.

SASSAKI, R. K. Atualizações semânticas na inclusão de pessoas: Deficiência mental ou intelectual? Doença ou transtorno mental? Revista Nacional de Reabilitação, ano 9, n. 43, p. 9-10, mar./abr. 2005. Disponível em: <http://www.pjpp.sp.gov.br/wp-content/uploads/2013/12/21. pdf $>$. Acesso em: 10 abr. 2014.

SCUSSIATTO, Caroline Carminatti. Inclusão: percursos e experiências educacionais no Brasil e na Itália. Informática na Educação: teoria e prática, Porto Alegre, v. 18, n. 2, p.19-37, jul./dez. 2015. Disponível em: <http://seer.ufrgs.br/index.php/InfEducTeoriaPratica/article/ view/52338/36444>. Acesso em: 11 abr. 2016

SILVA, Nara Liana; FURTADO, Adelaine Vianna. Inclusão no trabalho: a vivência de pessoas com deficiência intelectual. Interação em Psicologia, v. 16, n. 1, jan. 2013. Disponível em: <http://ojs.c3sl.ufpr.br/ojs/index.php/psicologia/article/view/23012/19719>. Acesso em: 11 abr. 2016.

SILVA, A. G.; PALHANO, E. G. S. Formação profissional: uma alternativa inclusiva para pessoas com deficiência. REUNIÃO ATUAL DA ANPED, 28. Caxambu, 2005.

TOLDRÁ, R. C.; MARQUE, C. B.; BRUNELLO, M. I. B. Desafios para a inclusão no mercado de trabalho de pessoas com DI: experiências em construção. Rev. Ter. Ocup. Univ. São Paulo, v. 21, n. 2, p. 158-165, maio/ago. 2010. Disponível em: <http://www.revistas.usp.br/rto/article/ viewFile/14099/15917>. Acesso em: 28 abr. 2014. 
CARDOSO, Laysa Karoline, KERN, Cristina Adriana Rodrigues. Capacitação da pessoa com...

VIOLANTE, Rômulo Rodrigues; LEITE, Lúcia Pereira. Employment of people with disability: an analysis of social inclusion in the job market in the city of Bauru, SP. Cad. psicol. soc. trab., São Paulo ,v. 14, n. 1, p. 73-91, jun. 2011. Disponível em: <http://pepsic.bvsalud.org/scielo. php?script=sci_arttext\&pid=S1516-37172011000100007\&lng=pt\&nrm=iso $>$. Acesso em: 11 abr. 2016.

Submissão em: 05/12/2014

Revisão em: 04/04/2016

Aceite em: 29/05/2016

Laysa Karoline Cardoso é graduada em Psicologia pela Universidade do Extremo Sul Catarinense. Endereço: UNESC - Psicologia. Av. Universitária, 1105 - Bairro Universitário. Cricuúma, SC. CEP: 88806-000 E-mail: laysakc@hotmail.com

Cristina Adriana Rodrigues Kern é professora do Curso de Graduação em Psicologia, Universidade do Extremo Sul Catarinense. Mestre em Psicologia Clínica. E-mail: cristinakern04@yahoo.com.br 